\title{
Photogrammetry: a Non-Invasive and Objective Method for Detecting Locomotion Problems in Broiler Chickens
}

http://dx.doi.org/10.1590/1806-9061-2015-0079

\section{-Author(s)}

\author{
Mendes AS \\ Paixão SJ" \\ Sikorski RR' \\ Bonamigo DV"I \\ Morello MG"II \\ Ponzoni RAR'
}

Department of Agronomy. Technological Federal University of Paraná, Dois Vizinhos, PR, Brazil.

" Undergraduate students at the Animal Sciences Department, Federal University of Santa Maria (UFSM), Rio Grande do Sul, Brazil;

III Purdue University, West Lafayette, IN, U.S.A.

\section{ABSTRACT}

Locomotion problems in broiler chickens can cause economic losses of up to $40 \%$ of the total revenues due to carcass condemnation and downgrading at processing. Leg disorders, such as femoral lesions, tibial dyschondroplasia, and spondylolisthesis, substantially impact the welfare of chickens as these disorders can prevent birds from reaching the feeders and drinkers, thus reducing feed and water intake. The most important issues related to broiler welfare reported in the last two decades are their growing sensitivity to metabolic and locomotion problems due to the fast growth rates and inactivity. Traditional methods for the determination of gait score include the manual scoring of animal behavior in the broiler house. Recorded video images can also be used for manual scoring of chicken gait score. However, scoring of some animal-based information by human experts and manual methods remain difficult, time consuming and expensive when implemented at farm level. In an effort to objectively detect leg disorders, this study aimed at validating the photogrammetry technique as a non-invasive method for identifying locomotion problems in broilers. Photogrammetry allows determining the geometric properties of broilers from digital photos that are processed and analyzed using a computer software. Results obtained using photogrammetry were tested for their correlation with those obtained by accepted methodologies, including gait score and macroscopic examination of femoral degeneration and tibial dyschondroplasia. The photogrammetry results agreed with the results of the afore mentioned accepted methods.

\section{INTRODUCTION}

Due to consumer pressure, livestock production systems have started to apply management practices to provide proper welfare conditions of intensively-reared animals. In this context, good animal welfare practices have become a marketing strategy to attract consumers (Mendes et al., 2012). Thus, adequate and non-invasive methods to assess animal welfare, such as photogrammetry, are essential to ensure good animal welfare for broiler chickens.

The most important broiler welfare issues reported in the last two decades are the increasing incidence of metabolic and locomotion problems due to the fast growth rates and lack of physical activity. On commercial farms, broiler chickens present low levels of activity, particularly those reared in high stocking densities during the last weeks of the growing period (Aydin et al., 2010).

Locomotion disorders negatively affect the performance and welfare of intensively-reared animals, and can negatively impact the profitability of livestock production. Leg abnormalities in poultry may deprive birds from locomotion freedom, which leading to suffering, discomfort, fear and distress during rearing. Bokkers et al. (2007) found 
that the high body weight of modern broiler strains can be considered a physical constraint to physical activity and normal behavior. Moreover, lameness can dramatically change the feeding strategy and impact bird performance (Weeks et al., 2000). For this reason, researchers have studied the development of locomotion problems in details in an effort to obtain valid techniques that allow for the objective detection of locomotion problems (Pelícia et al., 2012).

The muscle growth rate of modern broiler strains is higher than bone and tendon growth, and consequently, they are notable to support the high body weight of these birds (Bokkers et al., 2007). Weak bones and tendons can result in spondylolisthesis, ruptured gastrocnemius tendon, separation of the proximal femoral epiphysis, dyschondroplasia, backward bending of the proximal tibia, epiphyseitis (osteochondrosis), as well as pressure-induced microfractures at the diaphysis of the proximal tibia, which can be substantially painful for heavy chickens that try to stand and walk in this condition (Julian, 2005).

Tibial dyschondroplasia is an abnormal epiphyseal plate of the tibia bone, characterized by the presence of a white cartilage mass that extends to the metaphysis, where the trabecular bone is usually present (Capela e Silva et al., 2010). Insufficient ossification of this cartilage leads to fractures, infections and other disorders of the epiphyseal plate (Farquharson \& Jeffries, 2000).

An accepted and commonly used method to measure broiler welfare is gait score, developed by Kestin et al. (1992) and later adapted by Garner et al. (2002). It consists of manually scoring animal postures and gait by observing birds walking. Although gait score is a valid method to identify locomotion problems, it depends on the observer's interpretation, and therefore it is subjective, as well as time consuming and substantially expensive when used at farm level (Aydin et al., 2010).

Webster et al. (2008) stated that gait score is not accurate, as during this test birds are stimulated to walk more than they would normally do. This greater effort to walk fast or to run directly affects locomotion patterns and scores. Moreover, when exposed to novelty and experiencing fear, chickens may ignore pain and discomfort, which also affects the gait score. In addition, Bokkers \& Koene (2003) reported that chickens may be motivated to walk long distances to reach feeders and drinkers, which may also influence their locomotion patterns. However, Aydin et al. (2010), found a non-linear relationship between gait score and broiler chicken activity, with birds that scored 3 in a 0-3 gait-score scale presenting the highest activity level.

Locomotion problems, such as femoral degeneration and tibial dyschondroplasia, can also be identified by macroscopic examination, which consists of visually scoring the lesions on the affected region of the tibia and femur. For tibial dyschondroplasia, cartilage thickening in the epiphyseal growth plate is examined, whereas for femoral degeneration, the integrity of the articular cartilage of the proximal femoral epiphysis is evaluated (Almeida Paz et al., 2005; Fernandes et al., 2012). Macroscopic examinations, however, can also be time consuming and require previous sacrifice of the studied animal.

Given the substantial negative impact of locomotion disorders on livestock performance, researchers have sought new non-invasive methods for objectively identifying leg problems, aiming at improving animal welfare. Behavior assessment by image-analysis technologies has been widely used to assess animal welfare. Dawkins et al. (2001), for instance, proposed a method using optical flow (motion patterns) to analyze the behavior of commercial broiler chickens from videos recorded by inexpensive cameras. Dawkins et al. (2013) used video cameras to record the behavior of broiler chickens and to assess their welfare using computer-recognized individual stances, such as sitting and walking.

Photogrammetry is a method for obtaining geometric properties of objects, humans and animals using digital photos processed and analyzed by a software program. Photogrammetry has been used by physiotherapists (Sacco et al., 2007) to evaluate human posture and quantify health issues related to postural issues (lunes et al., 2005). Therefore, photogrammetry could be used to objectively identify welfare problems, such as leg disorders in poultry.

This study aimed at validating photogrammetry as a non-invasive method for identifying locomotion disorders in broilers. The results obtained using photogrammetry were correlated with those obtained by accepted methodologies, such as gait score and macroscopic identification of femoral degeneration and tibial dyschondroplasia.

\section{MATERIAL AND METHODS}

This study was conducted in a $1200-\mathrm{m}^{2}$ commercial broiler house, located in south-eastern state of Paraná

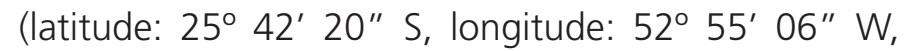
altitude: $541 \mathrm{~m})$, Brazil, in September and October of 2011. 
In total, 40 (20 males and 20 females) Cobb® broiler chickens were randomly selected from a broiler house $(125 \times 12 \mathrm{~m})$ housing 22,500 birds. The birds were obtained from the Pluma Agroavícola ${ }^{\circledR}$ hatchery and kept in a $4.0-\mathrm{m}^{2}$ area in one end of the broiler house to allow video recording. Birds were identified by leg bands placed on theirs hanks and their backs were marked with a non-toxic yellow ink. The experimental birds were weekly checked for locomotion disorders from 21 to 42 of life days of age using photogrammetry (lunes et al., 2005) and gait score (Kestin et al., 1992; Garner et al., 2002).

Gait score was determined in all birds, which were examined by a trained observer for five minutes once a week. Gait was scored in a 0-2 scale, according to walking ability (Garner et al., 2002): 0 - no walking impairment; 1 - obvious walking impairment; 2 severe walking impairment. Gait score results were then correlated with the photogrammetry results.

Birds were photographed using a digital camera (resolution of $1600 \times 1200$ pixels) placed at 0.2$\mathrm{m}$ from the floor to allow photographing the entire body of the chickens, at a distance of $2.4 \mathrm{~m}$. A black plastic canvas was used as background to allow for a better contrast when capturing the images. Birds were weekly photographed three times (replicates), once per minute, for each of three views: frontal, left lateral and right lateral views. Therefore, each of the 40 experimental chickens was photographed nine times weekly (at 21 days of age and at 42 days of age).

The digital images were processed using the software program CorelDRAWGraphics suite $X 8^{\circledR}$, which allowed digitally tracing the lines that establish the angles of the birds' postures. Figure 1 illustrates the posture angles evaluated on the frontal images. The angle between the tibia and the femur was designated as FF in Figure 1, where as FM represents the angle between the medial malleolus (distal portion of tibia) and the center of the foot.

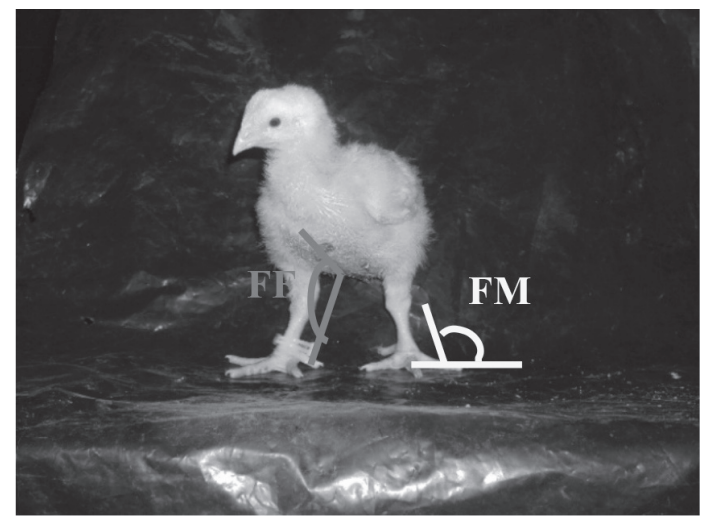

Figure 1 - Frontal Image of Chicken. FF angle between the Tibia and Femur; FM: angle between the medial malleolus (distal portion of Tibia) and the center of the foot.
Figure 2 illustrates the right and left lateral images of a chicken. The angle between the tibia and femoral axis was designated as LF in the left leg (left view) and RF in the right leg (right view), whereas LM and RM represent the angle between the medial malleolus (distal portion of tibia) and the center of the foot of the chicken left and right sides, respectively.
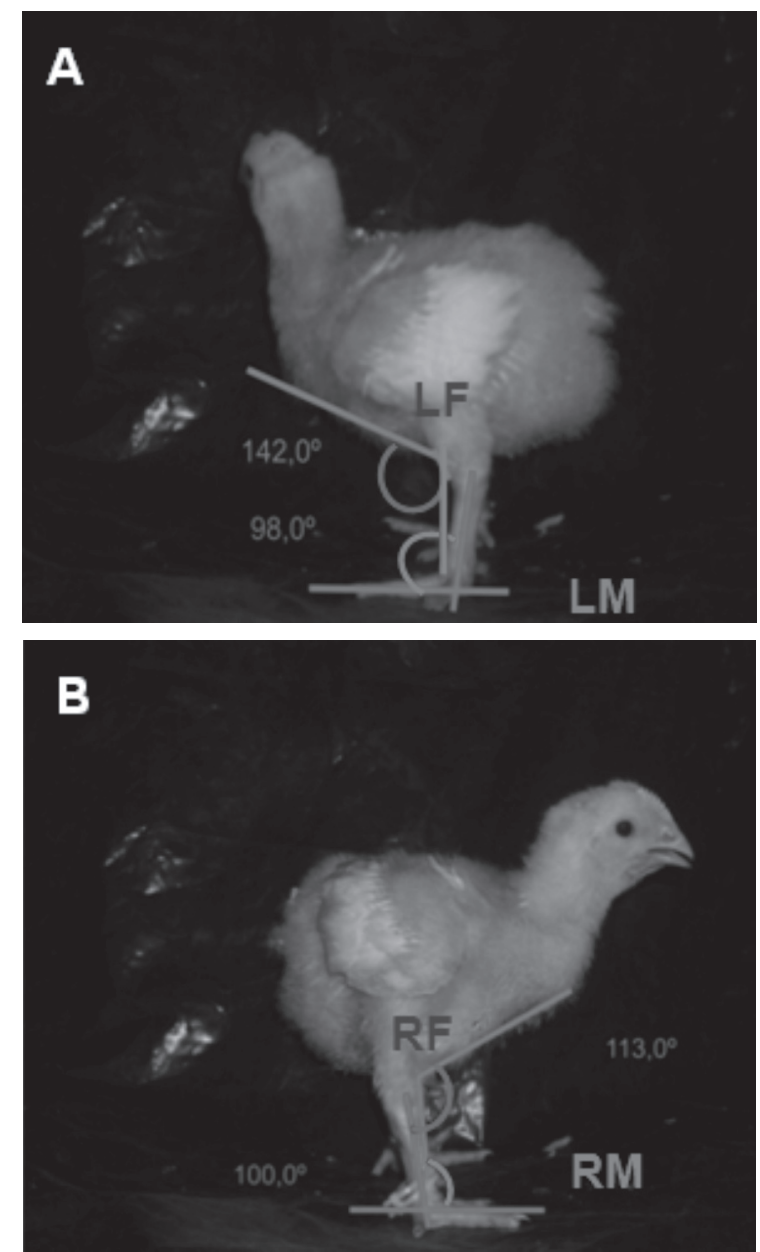

Figure 2 - Left (A) and Right (B) images of a chicken. LF, RF angle between the Tibia and Femur of the left and right legs, respectively. LM, RM: angle between the medial malleolus (distal portion of Tibia) and the center of the foot of the left and right legs, respectively.

The angles obtained by photogrammetry were then compared with the angles measured during the macroscopic examinations for femoral degeneration (Almeida Paz et al., 2010) and tibial dyschondroplasia (Almeida Paz et al., 2005) at the processing plant in the carcasses of the broilers slaughtered at 42 days of age. Tibial dyschondroplasia was assessed according to the thickening of the epiphyseal growth plate cartilage (Tselepis et al., 1996; Almeida Paz et al., 2005), whereas femoral degeneration according to the integrity of the articular cartilage of the proximal femoral epiphysis (Fernandes et al., 2012).

At the processing plants, the tibiae and femora were removed and their lengths measured using a 
caliper to evaluate the bilateral symmetry between the two legs. The proximal femoral epiphysis of each leg was examined and scored according to the 0-2 scale described by Almeida Paz et al. (2010): 0 intact epiphysis; 1 - early lesion, i.e., the bone is not completely covered by articular cartilage; 2 - Epiphysis with severe lesion, i.e., the apparent boundaries of the femoral head no longer existed. Tibial growth plate cartilage thickness was scored according to the 0-2 scale described by Almeida Paz et al. (2005): 0 - growth cartilage is not thickened; 1 - cartilage thickness between 1 and $3 \mathrm{~mm}$; 2 - cartilage thickness greater than $3 \mathrm{~mm}$.

Data were submitted to analysis of variance (ANOVA), applying the General Linear Models (GLM) procedure of Statistical Analysis System software (version 8.2) (Cruz, 2001). Means of tibial and femoral angles, obtained by macroscopic examinations, were compared between right and left legs using Tukey's test $(p \leq 0.05)$. Photogrammetry results were correlated with gait score and macroscopic examination results for tibial dyschondroplasia and femoral degeneration by Pearson's correlation test $(p \leq 0.05$ and $p \leq 0.01)$.

\section{RESULTS AND DISCUSSION}

Table 1 shows the Pearson's coefficient of the correlation between gait scores and photogrammetry results of male and female chickens obtained weekly from 21 to 42 days of age. Positive correlation coefficients indicate that the wider the measured angle, the greater was the gait score, and therefore, the more severe was the locomotion disorder, whereas negative coefficients indicate that the wider the angle measured, the lower was the gait score, and thus, the less severe was the locomotion disorder.

Photogrammetry results of FF and FM angles in 35 -day-old male chickens were positively $(p<0.05)$ correlated with gait score results. In addition, in 42-day-old male chickens, all the angles between the medial malleolus and center of the foot (FM, LM and RM) obtained by photogrammetry were positively correlated $(p<0.05)$ with gait score. Therefore, the wider the angle between the medial malleolus and the center of the foot, the greater the gait score, and therefore, the more severe was the locomotion disorder in 42-day-old male chickens. Also, the wider the frontal angles between the tibia and the femur and between the medial malleolus and the center of the foot, the more severe was the locomotion disorder in 35-day-old male chickens.
Table 1 - Pearson's Correlation Coefficient for comparing angle results obtained from Photogrammetry with results from Gait Score for male and female chickens of 21 through 42 days of age.

\begin{tabular}{|c|c|c|c|}
\hline \multirow[t]{2}{*}{ Age (days) } & \multirow[t]{2}{*}{$\begin{array}{c}\text { Angles from } \\
\text { Photogrammetry }\end{array}$} & \multicolumn{2}{|c|}{$\begin{array}{c}\text { Pearson's Correlation Coefficient } \\
\text { Photogrametry vs. Gait Score }\end{array}$} \\
\hline & & Male & Female \\
\hline \multirow[t]{6}{*}{21} & RF & -34.1 & 28.18 \\
\hline & RM & 28.4 & -34.91 \\
\hline & $\mathrm{LF}$ & -41.57 & 15.94 \\
\hline & LM & 43.41 & -12.38 \\
\hline & $\mathrm{FF}$ & 7.73 & -6.86 \\
\hline & FM & -18.03 & -10.64 \\
\hline \multirow[t]{6}{*}{28} & RF & -15.74 & -28.49 \\
\hline & RM & 13.83 & 19.1 \\
\hline & $\mathrm{LF}$ & -1.49 & -28.93 \\
\hline & LM & -40.59 & 8.51 \\
\hline & $\mathrm{FF}$ & -1.11 & 22.26 \\
\hline & FM & -7.89 & -1.79 \\
\hline \multirow[t]{6}{*}{35} & RF & 16.44 & 29.79 \\
\hline & RM & -7.13 & $-62.47 * *$ \\
\hline & $\mathrm{LF}$ & 32.16 & $47.62 *$ \\
\hline & LM & -10.47 & -25.99 \\
\hline & $\mathrm{FF}$ & $52.06 *$ & -11.74 \\
\hline & FM & $47.24^{*}$ & 11.59 \\
\hline \multirow[t]{6}{*}{42} & RF & 40.06 & $53.42 *$ \\
\hline & RM & $75.56^{\star}$ & 8.07 \\
\hline & $\mathrm{LF}$ & 54.68 & 9.49 \\
\hline & LM & $71.49 *$ & -31.35 \\
\hline & $\mathrm{FF}$ & 59.23 & $-51.06 *$ \\
\hline & FM & 73.21 * & -21.52 \\
\hline
\end{tabular}

** Significant at 99\% Confidence Level;

* Significant at 95\% Confidence Level.

FF, LF, RF: Angle formed by the Tibia and Femur axis from the chicken's front, left and right views, respectively.

FM, LM, RM: Angle between the medial malleolus (distal portion of Tibia) and the center of the foot from the chicken's front, left and right views, respectively.

These results suggest that photogrammetry may be a valid technique for detecting leg disorders in heavy broilers, which are likely to develop severe locomotion problems due to their heavy body weight. Sorensen et al. (2000) reported that the incidence of severe locomotion problems in broilers increases with age and that males exhibited greater leg weakness than females at all ages, which the significant correlations between photogrammetry and gait score results of older males in the current study.

Kestin et al. (2001) reported that high growth rates and heavy body weights substantially affect the locomotion of broilers. High body weight requires a strong skeleton to support it, and therefore, when the skeleton of broilers is not fully developed, higher gait scores are recorded (Corr et al., 2003). However, the nature of the apparent relationship of lameness and 
body weight with reduced physical activity in broilers remains unclear in literature (Hester, 1994).

The significant correlation of the angle between the medial malleolus and the center of the foot and gait score obtained in 42-day-old males indicates that this angle may be a valid indicator of the severity of locomotion problems. Photogrammetry results of the RM and LF angles of 35-day-old females and of RF and FF angles of 42-day-old females were also correlated $(p<0.05)$ with gait score (Table 1$)$, possibly because they were older (Sorensen et al., 2000) and heavier compared with younger females. The correlation coefficient between gait score and bone angles was negative for RM (-62.47) and positive for LF (47.62) in 42 day-old females. Therefore, the wider the angle between the medial malleolus and the center of the foot in 42-day-old females, the lower the gait score, and therefore, the less severe was the locomotion disorder, whereas the wider is the angle between the tibia and femur, the more severe was the locomotion disorder.
Sanotra et al. (2001) also found significant correlation between varus-valgus angles and gait score, and stated that a single parameter, such as varus-valgus is enough to detect a leg disorder in broiler chickens. Accordingly, Fernandes et al. (2012) found a significant correlation $(p<0.01)$ between valgus deformity and gait score in both right and left legs of 35-day-old chickens. However, the authors also found that birds that presented walking difficulty (gait score of 1 and 2) did not have severe femoral degeneration or tibial dyschondroplasia.

Table 2 shows the Pearson's correlation coefficients of photogrammetric angles with gait score and macroscopic femoral degeneration and tibia dyschondroplasia results obtained in the carcasses of 42 day-old chickens.

Gait score was negatively correlated $(p<0.05)$ with the macroscopic examination of femoral degeneration results both in the right and left legs of 42 day-old male chickens (Table 2), with correlation coefficients of -74.67 for both legs.

Table 2 - Pearson's Correlation Coefficients for the comparison between Photogrammetry and gait score, as well as macroscopic examination results of femural degeneration and tibia dischondroplasia in 42 day-old chickens.

\begin{tabular}{|c|c|c|c|c|c|}
\hline Angles from Photogrammetry & $\begin{array}{l}\text { Gait } \\
\text { Score }\end{array}$ & $\begin{array}{c}\text { Right } \\
\text { Tibia Angle }\end{array}$ & $\begin{array}{c}\text { Left } \\
\text { Tibia Angle }\end{array}$ & Right Femur Angle & Left Femur Angle \\
\hline & \multicolumn{5}{|c|}{ Macroscopic Examination - Males } \\
\hline RF & 40.06 & 29.19 & 7.94 & 7.12 & -40.84 \\
\hline RM & $75.56^{*}$ & -11.28 & 12.44 & -64.49 & -58.58 \\
\hline LF & 54.68 & 40.17 & 12.55 & 0.28 & -68.7 \\
\hline LM & $71.49 *$ & -2.58 & -47.34 & -59.16 & $-89.59 * *$ \\
\hline $\mathrm{FF}$ & 59.23 & 32.83 & -24.71 & -20.17 & $-95.76 * *$ \\
\hline FM & $73.21 *$ & 29.01 & -24.56 & -34.17 & $-94.34 * *$ \\
\hline Gait Score & & 10.37 & 4.64 & $-74.67 *$ & $-74.67 *$ \\
\hline Right Tibia Angle & 10.37 & & 44.72 & -21.82 & -21.82 \\
\hline Left Tibia Angle & 4.64 & 44.72 & & -9.76 & 29.28 \\
\hline Right Femur Angle & $74.67 *$ & -21.82 & -9.76 & & 42.86 \\
\hline \multirow[t]{2}{*}{ Left Femur Angle } & $74.67 *$ & -21.82 & 29.28 & 42.86 & \\
\hline & \multicolumn{5}{|c|}{ Macroscopic Examination - Females } \\
\hline $\mathrm{RF}$ & $53.42^{*}$ & 8.64 & -18.32 & -8.31 & 1.09 \\
\hline RM & 8.07 & 49.77 & $86.03 * *$ & -3.19 & 14.63 \\
\hline LF & 9.49 & -14.12 & -41.05 & -55.25 & -16.01 \\
\hline LM & -31.35 & -1.2 & 55.29 & 14.58 & 30.46 \\
\hline $\mathrm{FF}$ & $-51.06^{*}$ & 0.2 & 25.67 & -11.04 & $65.57^{*}$ \\
\hline FM & -21.52 & 10.09 & 28.88 & 31.06 & $76.52^{*}$ \\
\hline Gait Score & & 62.55 & 44.23 & 60.19 & -7.88 \\
\hline Right Tibia Angle & 62.55 & & $70.71 *$ & 57.74 & 37.8 \\
\hline Left Tibia Angle & 44.23 & $70.71 *$ & & 40.82 & 26.73 \\
\hline Right Femur Angle & 60.19 & 57.74 & 40.82 & & 21.82 \\
\hline Left Femur Angle & -7.88 & 37.8 & 26.73 & 21.82 & \\
\hline
\end{tabular}

** Significant at $99 \%$ Confidence Level;

* Significant at 95\% Confidence Level.

FF, LF, RF: Angle formed by the Tibia and Femur axis from the chicken's front, left and right views, respectively.

FM, LM, RM: Angle between the medial malleolus (distal portion of Tibia) and the center of the foot from the chicken's front, left and right views, respectively. 
Photogrammetry results for the angles between the medial malleolus and center of the foot both in frontal (FM) and left side (LM) measures were significantly correlated $(p<0.01 ; p<0.05$, respectively) with the macroscopic detection of femoral degeneration in male chickens (Table 2). Also, the frontal measure of the angle between tibia and femur (FF) obtained photogrammetry was significantly correlated $(p<0.01)$ with macroscopic femoral degeneration results in male chickens (Table 2).

Table 2 shows that the photogrammetry results were also significantly correlated with those obtained during gross examination: RM with tibia dyschondroplasia, and FF and FM with femoral degeneration in the left leg of female chickens. In this case, the birds with wider angles in photogrammetry, also presented tibia dyschondroplasia and femoral degeneration when the affected regions were examined at slaughter. These results indicate that the measurement of the FF, LM and FM angles by photogrammetry may be used as an alternative to macroscopic examination to detect femoral degeneration in 42 day-old male chickens.

Leeson et al. (1995) stated that tibial dyschondroplasia is common in fast-growing male broiler chickens, with an incidence up to $49 \%$. Moreover, birds with lesions in their right tibia also presented lesions in their left tibia. Those authors also found that males presented higher incidence of tibial dyschondroplasia than females. This difference between males and females may be attributed to differences in feet and legs yield, since male present higher feet, legs and viscera yields, whereas female broiler chickens present higher breast meat yield (Santos et al., 2005). Sheridan et al. (1978) hypothesized that tibial dyschondroplasia may be associated with a major sex-linked gene.

There are evidences in literature that male broiler chickens present lower bone ash percentage than females, as a result of inadequate bone mineralization caused by their faster growth rate relative to females (Tablante et al., 2003).

Healthy broiler chickens spend approximately $73 \%$ to $76 \%$ of their time sitting during the last couple of weeks of the rearing cycle, even when not lame (Weeks et al., 2000). Therefore, it is important to identify the underlying causes of skeleton abnormalities related to metabolic diseases (Skinner \& Waldroup, 1995).

Considering the high incidence of leg disorders, such as tibial dyschondroplasia and femoral degeneration, and their substantial impact on the performance and welfare of commercial broiler chickens, an effective and objective method for detecting lameness is essential to further improve their welfare and performance. As reported in the present study, the methods currently applied to assess locomotion problems in broilers, such as gait score can be time-consuming, whereas macroscopic examination of joints and bones requires the previous sacrifice of the birds. This study showed that photogrammetry is a promising alternative to the commonly accepted methods for detecting leg disorders in broiler chickens. Sex and age differences in the incidence of leg disorders must be taken into account when using photogrammetry as a reliable method for detecting lameness.

Relationships between productivity, stress, and developmental instability suggest that the interests of domestic animals, farmers and scientists, to some extent, are congruent, and that improvements in developmental instability through artificial selection and better rearing conditions will favor all parties involved (Moller \& Manning, 2003).

\section{CONCLUSIONS}

Photogrammetry is a promising non-invasive and objective method for detecting locomotion disorders, and therefore, indicating animal welfare levels. The results obtained with photogrammetry shown strong agreement with the results of commonly accepted methods for detecting lameness, such as the gait score and macroscopic examination of tibial dyschondroplasia and femoral degeneration. Therefore, photogrammetry can be applied to detect locomotion problems in male and female broiler chickens, particularly at the ages of 35 and 42 days.

\section{REFERENCES}

Almeida Paz ICL, Mendes AA, Takita TS, Vulcano LC, Guerra PC, Wechsler FS. Comparison of techniques for tibial dyschondroplasia assessment in broiler chickens. Revista Brasileira de Ciências Avícolas 2005;7(1):2731

Almeida Paz ICL, Garcia RG, Bernardi R, Nääs IA, Caldara FR, Freitas LW, et al. Selecting appropriate bedding to reduce locomotion problems in broilers. Brazilian Journal Poultry Science 2010;12:189-195.

Aydin A, Cangar O, Eren Ozcan S, Bahr C, Berckmans D. Application of a fully automatic analysis tool to assess the activity of broiler chickens with different gait scores. Computers and Electronics in Agriculture 2010;73:194-199.

Bokkers EAM, Koene P. Behaviour of fast- and slow-growing broilers to 12 weeks of age and the physical consequences. Applied Animal Behaviour Science 2003;81:59-72.

Bokkers EAM, Zimmerman PH, Bas Rodenburg T, Koene P. Walking behaviour of heavy and light broilers in an operant runway test with varying durations of feed deprivation and feed access. Applied Animal Behaviour Science 2007;108:129-142. 
Capela e Silva F, Lamy E, Reis JC, Potes JC, Pereira A, Cabrita AS. Expressão imunoistoquímica da proteína S-100 na discondroplasia da tíbia [S-100 protein immunostaining in tibial dyschondroplasia]. Arquivos Brasileiros de Medicina Veterinária e Zootecnia 2010;62(2):495-498.

Corr SA, Gentle MJ, Mccorquodale CC, Bennett D. The effect of morphology on walking ability in the modern broiler:a gait analysis study. Animal Welfare 2003;12(2):159-171.

Cruz CD. Programa Genes: versão Windows; aplicativo computacional em genética e estatística. Viçosa: Universidade Federal de Viçosa; 2001. p.648.

Dawkins MS. How can we recognize and assess good welfare? In: Broom DM, editor. Coping with challenge: welfare in animals including humans. Dahlem workshop report. Berlin: Dahlem University Press; 2001. p.63-76

Dawkins MS, Cain R, Merelie K, Roberts SJ. In Search of The behavioural correlates of optical flow patterns in the Automated assessment of broiler chicken welfare. Applied Animal Behaviour Science 2013;145:44-50

Farquharson C, Jeffries D. Chondrocytes and longitudinal bone growth: the development of tibial dyschondroplasia. Poultry Science 2000;79:9941004.

Fernandes BCS, Martins MRFB, Mendes AA, Almeida Paz ICL, Komiyama CM, Milbradt EL, Martins BB. Locomotion problems of broiler chickens and its relationship with the gait score. Revista Brasileira de Zootecnia2012;41(8):1951-1955.

Garner JP, Falcone C, Wakenell P, Martin M, Mench JA. Field report scoring system and its use in assessing tibial dyschondroplasia in broilers. Brazilian Poultry Science 2002;43:355-363.

Hester PY. The role of environment and management on leg abnormalities in meat-type fowl. Poultry Science 1994;73:904-915.

lunes DH, Castro FA, Salgado HS, Moura IC, Oliveira AS, BevilaquaGrossi D. Confiabilidade intra e interexaminadores e repetibilidade da avaliação postural pela fotogrametria. Revista Brasileira de Fisioterapia 2005;9(3):327-34.

Julian RJ. Production and growth related disorders and other metabolic diseases of poultry - A review. The Veterinary Journal 2005;169:350369.

Kestin SC, Gordon S, Su G, Sorensen P. Relationships in broiler chickens of broiler chickens and its modification by lameness. Applied Animal Behaviour Science 2001;67:111-125.

Kestin SC, Knowles TG, Tinch AE. Prevalence of leg weakness in broiler chickens and its relationship with genotype. Veterinary Record 1992;131:190-194.
Leeson S, Diaz G, Summers JD. Poultry metabolic disorders and mycotoxins Ontario: University Books; 1995.

Mendes AS, Paixão SJ, Marostega J, Restelatto R, Oliveira PAV, Possent $J C$. Measurement of locomotor problems and pad lesions in broilers. Archivos Brasilerios de Zootecnia 2012;61(234):217-228.

Møller AP, Manning J. Growth and development instability. Veterinary Journal 2003;166:19-27.

Pelicia K, Aparecido Jr IM, Garcia EA, Molino AB, Santos GC, Berto DA, et al. Evaluation of a radiographic method to detect tibial dyschondroplasia lesions in broilers. Brazilian Journal Poultry Science 2012;14(2):71-158.

Sacco ICN, Alibert S, Queiroz BWC. Confiabilidade da fotogrametria em relação a goniometria para avaliação postural de membros inferiores. Revista Brasileira de Fisioterapia 2007;11(5):411-417.

Sanotra G, Loudand S, Damkjer J. Monitoring Leg Problems In Broilers:A survey of commercial broiler production in Denmark. World Poultry Science Journal 2001;57:55-69.

Santos AL, Sakomura NK, Freitas E. Estudo do crescimento, desempenho, rendimento de carcaça e qualidade de carne de três linhagens de frango de corte. Revista Brasileira de Zootecnia 2005:34(5):1589-1598.

Sheridan AK, Howlett CR, Burton RW. The inheritance of tibial dyschondroplasia in broilers. Brazilian Poultry Science 1978;19:491499.

Skinner JT, Waldroup PW. Allometric bone development in floor-reared broilers. Journal Applied Poultry Research 1995:4:265-270.

Sorensen P, Su G, Kestin SC. Effects of age and stocking density on locomotion problems in broiler chickens. Poultry Science 2000;79:864870.

Tablante NL, Estevez I, Russek-Cohen E. Effect of perches and stocking density on tibial dyschondroplasia and bone mineralization as measured by bone ash in broiler chickens. Journal Applied Poultry Research 2003;12:53-59.

Tselepis C, Hoyland JA, Barber RE, Thorp BH, Kwan AP. Expression and distribution of cartilage matrix macromolecules in avian tibial dyschondroplasia. Avian Pathology 1996;25:305-324.

Webster AB, Fairchild BD, Cummings TS, Stayer PA. Validation of a ThreePoint Gait-Scoring System for Field Assessment of Walking Ability of Commercial Broilers. Journal of Applied Poultry Research 2008;17:529539 .

Weeks CA, Danbury TD, Davies HC, Hunt P, Kestin SC. The behaviour between lameness, live weight, growth rate, age. Veterinary Record 2000;148(7):195-197. 
